\title{
ESTUDO DO COMPORTAMENTO DA TEMPERATURA E PRECIPITAÇÃO NOS PERÍODOS CHUVOSOS E MENOS CHUVOSOS EM BELÉM-PA EM ANOS DE FORTES EVENTOS DE EL NIÑO E LA NIÑA
}

\author{
José Augusto de Souza Júnior ${ }^{23}$ \\ Dimitrie Nechet ${ }^{24}$ \\ Maria do Carmo Felipe de Oliveira ${ }^{25}$ \\ Monik Fernandes de Albuquerque ${ }^{26}$
}

\begin{abstract}
RESUMO
El Niño e La Niña são fenômenos atmosféricos - oceânicos contrários, caracterizados por anomalias da temperatura das águas do Oceano Pacífico Tropical mudando padrões de vento e afetando os regimes de chuvas em regiões Tropicais e de Latitude médias. Este trabalho teve como objetivo estudar e comparar a média das Temperaturas do $\operatorname{Ar}(T)$, como Temperatura média (TMédia: Medias das 24 horas), Temperatura média compensada $((T 9+2 x T 21+T M i n+T M a x) / 5)$, Temperatura médias das 09:00 (T9) e 21:00 horas (T21), Temperaturas médias máximas (TMax) e mínimas (TMin) e a Precipitação Pluviométrica Total média (PRP) para anos de forte ocorrência de fenômeno El Niño (1982, 1983, 1990, 1993) e La Niña (1976, 1989) para o trimestre mais chuvoso (Fevereiro, Março e Abril) e trimestre menos chuvoso (Setembro, Outubro e Novembro) visando mostrar o comportamento da Temperatura do ar, na cidade de Belém-Pa, onde, praticamente não ocorreu alteração da superfície e proporcionar subsídios a outras pesquisas, entre as diversas maneiras de cálculos de Temperatura do Ar. Os Resultados mostram que as médias das Temperaturas (24 observações) e a temperatura compensada apresentaram valores muito próximos, enquanto que a média das temperaturas das 09:00 horas apresentaram valores mais elevados e das 21:00 horas apresentaram valores menos elevados quando comparados com a média das 24 horas e a média compensada. As médias de todas as Temperaturas obtidas apresentaram comportamentos próximos em anos de forte ocorrência de El Niño e La Niña durante o período chuvoso e período menos chuvoso, porém no período chuvoso, os valores foram menores e na época menos chuvosa foram maiores. Com relação à precipitação média mensal comparada

\footnotetext{
${ }^{23}$ Mestrando em Meteorologia Agrícola - Universidade Federal de Viçosa - UFV - jun086@gmail.com ; (31) 38851538 - Viçosa -MG.

24 Professor Adjunto 04 - Faculdade de Meteorologia - Universidade Federal do Pará - UFPA dimitrie@ufpa.br ; (91) 32017985 - Belém - PA.

${ }^{25}$ Professora Adjuntos 04 - Faculdade de Meteorologia - Universidade Federal do Pará - UFPA oliveiramaca@gmail.com ; (91) 32017985 - Belém - PA.

${ }^{26}$ Graduanda em Meteorologia - Universidade Federal do Pará - UFPA - albuquermf@hotmail.com ; (91) 32017985 - Belém - PA.
} 
com a Normal Climatológica, durante o ano todo, alguns meses apresentaram valores acima da Normal e outros meses abaixo da Normal, tanto nos anos de El Niño, como nos anos de La Niña.

Palavras-chave: Temperatura, Precipitação, Belém/PA.

\section{ABSTRACT}

El Niño and La Niña are contrary atmospheric - oceanic phenomena, characterized by anomalies of waters temperatures of the Tropical Pacific Ocean, changing wind standards and affecting rains regimes in Tropical and Average Latitudes region. This work had as objective to study and to compare the average of the Air Temperatures ( $T$ ), as average Temperature (TMédia: Average of 24 hours), compensated average Temperature ((T9+2xT21+TMin+TMax) /5), average Temperature of 09:00 (T9) and 21:00 hours (T21), average maximum (TMax) and minimum Temperatures (TMin) and average Total Pluviometric Precipitation (PRP) for years of strong occurrence of phenomenon El Niño (1982, 1983, 1990, 1993) and La Niña (1976, 1989) for the rainiest trimester (February, March and April) and less rainy trimester (September, October and November) aiming at to show the behavior of the air Temperature, of the city of Belém-Pa, where, it practically did not occur alteration of the surface and to provide subsidies to other researchs, between the diverse ways of calculations of Air Temperature. The Results show that the averages of the Temperatures (24 observations) and the compensated temperature had presented very next values, whereas the average of the temperatures of 09:00 hours had presented higher values and of the 21:00 hours had presented less values when compared with the average of the 24 hours and the compensated average. The averages of all gotten Temperatures had presented similar behaviors in years of strongly events of El Niño and La Niña during the rainy period and less rainy period, however in the rainy period, the values had been lesser and at the less rainy period they had been higher. Regarding to the monthly average precipitation compared with the Climatologic Normal, during all the year, some months had presented values above the Normal and other months below the Normal, as much in the years of El Niño, as in the years of La Niña.

Key-words: Temperature, Rain, Belém-Pa.

\section{INTRODUÇÃo}

Muito se tem perguntado a respeito das possíveis variações e mudanças climáticas, desde os aspectos da poluição atmosférica até a formação de ilhas de calor, devido ao uso indiscriminado dos recursos naturais e da ocupação urbana desordenada do homem, nas grandes cidades.

A cidade de Belém localiza-se às margens da Baia do Guajará e Rio Guamá, no estuário do Rio Pará, na Lat. $01^{\circ} 23^{\prime}$ S, Long. $048^{\circ} 29^{\prime} \mathrm{W}$ e altitude de $17 \mathrm{~m}$ acima do nível médio do mar, localizada em Zona Tropical, apresenta temperaturas do ar e umidade relativas muito elevadas durante todo o ano, apresentando um clima quente e úmido com uma grande incidência dos raios 
solares, os quais atingem a superfície quase que perpendicularmente justificando assim a quase que constante elevada temperatura do ar na cidade.

A Precipitação em Belém origina-se na maioria dos casos, devido ao aquecimento diferencial local, que propicia a formação de células convectivas locais durante o ano, no entanto, na época chuvosa (DEZ à MAI), a Zona de Convergência Intertropical (ZCIT), encontra-se sobre a área de Belém. Sabendo-se que a ZCIT é formada em função de uma faixa aquecida, gerando a confluência dos ventos Alísios de Nordeste do Hemisfério Norte e os Alísios de Sudeste do Hemisfério Sul, e estes são provenientes dos sistemas de alta pressão semi-permanentes do Atlântico Norte e Atlântico Sul, gerando movimentos ascendentes, o que caracteriza uma intensificação da Zona de Baixa Pressão. Assim, Belém produz maior quantidade de precipitação.

As variáveis meteorológicas, estando relacionadas com fenômenos de escala global, sofrem também influências dos fenômenos El Niño e La Nina que estão relacionados à anomalias oceânicas e atmosféricas na região equatorial do Oceano Pacífico.

Acredita-se que os fenômenos El Niño e La Niña sejam alguns dos principais responsáveis pelas flutuações globais do clima dentre todos os fenômenos atmosféricos, sendo que eles continuam sendo os mais polêmicos até os dias atuais, dada sua escala global de abrangência e sua extensa durabilidade temporal.

A fase negativa do El Niño Oscilação Sul - ENOS, está associada com a presença de água anomalamente quente, próxima à costa oeste da América do Sul e representa a forte mudança que sofre a circulação com o ramo ascendente (convecção intensa) sobre a região das águas aquecidas e o ramo descendente sobre a Amazônia e o Nordeste do Brasil, o que resulta na inibição de convecção e conseqüentemente diminuição de precipitação nessas áreas. O fenômeno La Niña apresenta comportamento inverso ao fenômeno El Niño, conseqüentemente provoca aumento da precipitação nas regiões norte e nordeste do Brasil.

Este trabalho tem como objetivo estudar a variabilidade interanual dos elementos meteorológicos como médias das temperaturas $(T)$ do ar $e$ Precipitação Pluviométrica (PRP) em quatro anos de forte ocorrência de El Niño (1982, 1983, 1990 e 1993) e dois anos de forte ocorrência de La Nina (1976 e 1989) em Belém do Pará com dados horários coletados na Estação Meteorológica Convencional do Aeroporto Internacional de Belém, à fim de quantificar a influência dos fenômenos El Niño e La Niña sobre os elementos meteorológicos, e também realizar um detalhamento do comportamento desses elementos meteorológicos, o que possibilitará a oportunidade de novos estudos derivados dos resultados obtidos, envolvendo os trimestres mais chuvosos e os trimestres menos chuvosos na região, na época de ocorrência dos fenômenos El Niño e La Niña.

\section{MATERIAIS E MÉTODOS}

\subsection{LOCALIZAÇÃO DA ÁREA}

Foram utilizados dados da Estação Meteorológica Convencional do Aeroporto Internacional de Belém, com as coordenadas Lat. 01 ${ }^{\circ} 23^{\prime} \mathrm{S}$, Long. 048 $29^{\prime} W$ e Alt. 17 metros, do então Serviço Regional de Proteção ao Vôo de 
Belém (SRPV-BE), que operava em horário contínuo, durante as 24 horas do dia.

\subsection{OBTENÇÃO DE DADOS}

Foram utilizados dados horários de temperatura do ar referentes às 24 observações horárias e dados de precipitação mensal, referentes a seis anos, sendo quatro desses em que houve a ocorrência forte do fenômeno El Niño: 1982, 1983, 1990 e 1993, e dois anos de ocorrência forte do fenômeno La Nina: 1976 e 1989.

\subsection{TRATAMENTO DE DADOS}

Partindo do princípio em que obtém valores precisos das 24 observações diárias de Temperatura do ar, foi possível encontrar a temperatura média diária (TMédia) de acordo com recomendações da OMM (Organização Meteorológica Mundial) onde utilizaram-se as 24 temperaturas observadas em intervalos cronológicos iguais durante as 24 horas seguidas:

$$
\text { TMédia }\left({ }^{\circ} C\right)=\frac{T 00 h+T 01 h+T 02 h+\ldots+T 23 h}{24}
$$

Também foi possível, através de dados horários, se obter a Média Compensada da Temperatura do ar (TMédiaCompensada), através da fórmula abaixo utilizada pelo Instituto Nacional de Meteorologia (INMET):

$$
\text { TMédiaCompensada }\left({ }^{\circ} \mathrm{C}\right)=\frac{T 09 h+2 x T 21 h+T M i n+T M a x}{5}
$$

Com base nos cálculos obtidos de: Temperatura média horária (variação diurna) (T), Temperatura média das 09:00 horas local (T9) e Temperatura média das 21:00 horas local (T21), sendo que respectivas médias representam a média aritmética horária de todas as temperaturas do mesmo horário no trimestre estudado; Temperatura média diária, Temperatura máxima média (TMAX) e Temperatura média mínima (TMIN), que representam as médias diárias de todas as temperaturas do mesmo dia no trimestre estudado; foram elaboradas figuras para análise, bem como, foi possível também estudara variabilidade da Temperatura média mensal do ar e total médio mensal da Precipitação Pluviométrica (PRP) em anos de forte ocorrência dos fenômenos El Niño e La Niña, comparada com a Normal Climatológica (INMET)(1961 a 1990), a fim de melhor entendermos a influência desses fenômenos na cidade de Belém-Pa.

\section{RESULTADOS E DISCUSSÃO}

3.1 TEMPERATURAS MÉDIA, MÉDIA COMPENSADA, 09:00 HORAS E 21:00 HORAS 
Nas Figuras 01 e 02 são mostradas as médias das temperaturas médias diárias (24 horas), temperatura média compensada, temperatura média das 09 horas e temperatura média das 21 Horas, sendo estas representativas para cada dia dos meses mais chuvosos (FEV, OUT, NOV) e para os anos representativos de El Niño (1982, 1983, 1990, 1993).

Observa-se que as médias das temperaturas são mais elevadas no período menos chuvoso, porém, em ambos os períodos, elas apresentam comportamentos próximos, ou seja, as curvas da média aritmética calculada com as 24 observações diárias e da média compensada se aproximam enquanto que a curva das médias das temperaturas das 09:00 horas são mais elevadas e as curvas das temperaturas das 21:00 horas são menos elevadas, ou seja, elas se distanciam da média considerada padrão (24 observações).

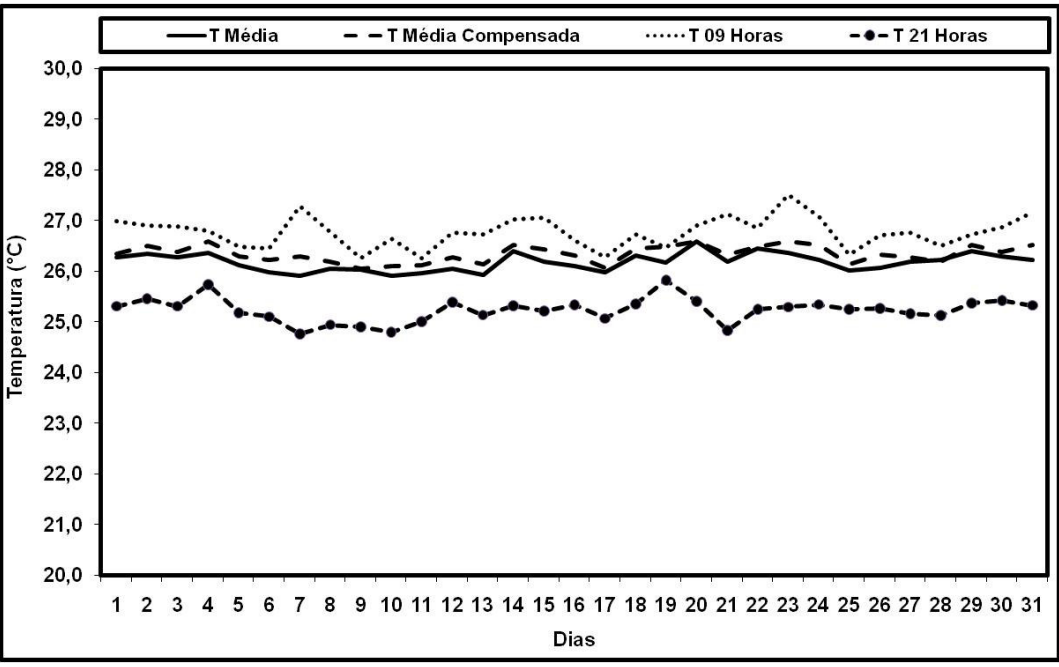

Figura 01. Médias das Temperaturas Média, Média Compensada, 09h e $21 \mathrm{~h}$ Para o Trimestre Mais Chuvoso (JAN, FEV, MAR) em Anos de El Niño.

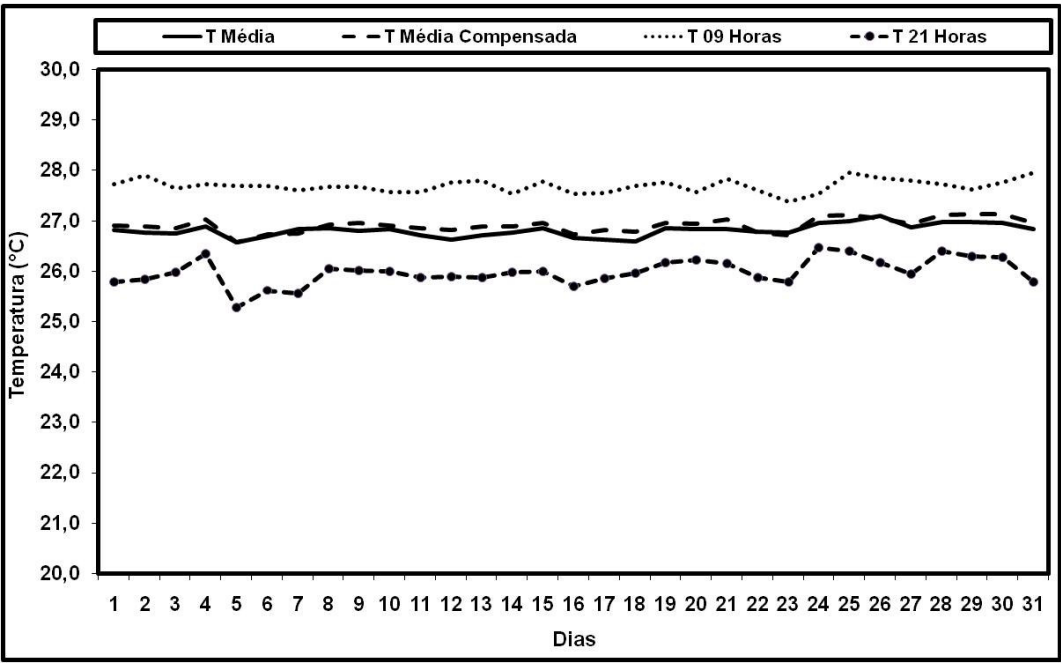

Figura 02. Médias das Temperaturas Média, Média Compensada, 09h e $21 \mathrm{~h}$ Para o Trimestre Menos Chuvoso (SET, OUT, NOV) em Anos de El Niño. 
As Figuras 03 e 04 mostram as médias das Temperaturas médias diárias, Temperatura média compensada, Temperatura das 09:00 Horas e 21:00 Horas para os anos representativos da ocorrência do fenômeno La Niña (1976 e 1989) para os trimestres mais chuvoso e menos chuvoso em Belém do Pará.

Observa-se o mesmo comportamento das Figuras 01 e 02, porém, notase que em anos de El Niño todas as médias de temperatura são mais elevadas, ou seja, em anos de El Niño e La Niña, no período mais chuvoso, as médias foram de $26,2^{\circ} \mathrm{C}$ e $25,5^{\circ} \mathrm{C}$, respectivamente, ou seja, observamos um aumento da temperatura em anos de El Niño e uma diminuição em anos de La Niña.

Observa-se que a média das temperaturas das 09:00 horas e das 21:00 horas acompanham o comportamento das curvas das médias aritméticas e compensadas, mostrando ainda que a amplitude térmica das médias das temperaturas das 09:00 é menor que a amplitude térmica das 21:00 Horas quando comparadas com as médias aritméticas e compensadas. Esses resultados mostram que há a necessidade de conhecerem os desvios apresentados entre as diversas maneiras de cálculo das médias de temperatura (NECHET, 1998).

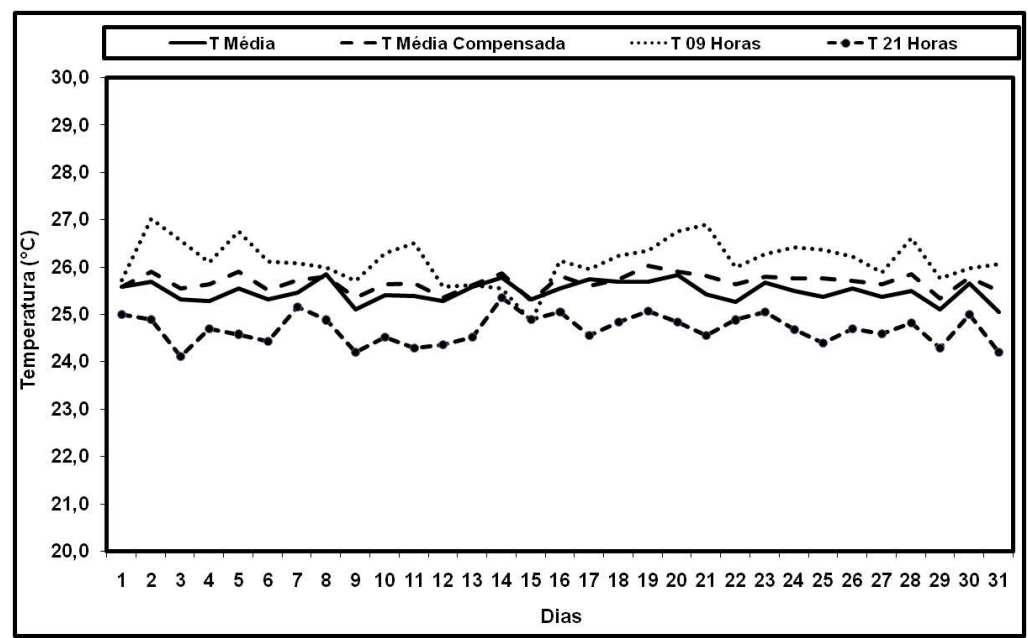

Figura 03. Médias das Temperaturas Média, Média Compensada, 09h e $21 \mathrm{~h}$ Para o Trimestre Mais Chuvoso (JAN, FEV, MAR) em Anos de La Niña.

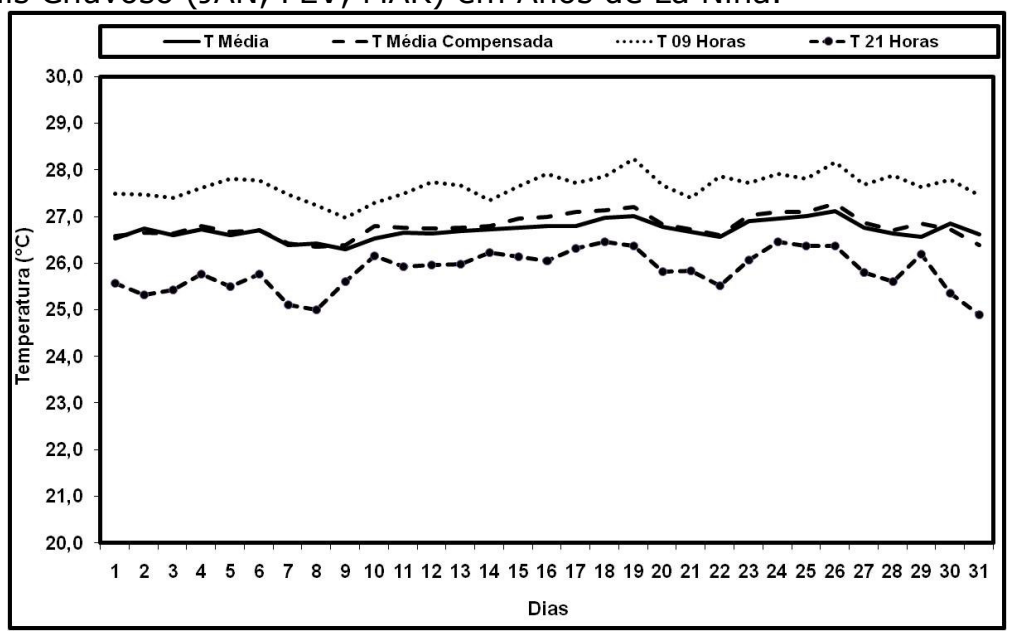

Figura 04. Médias das Temperaturas Média, Média Compensada, 09h e $21 \mathrm{~h}$ Para o Trimestre Menos Chuvoso (SET, OUT, NOV) em Anos de La Niña. 


\subsection{TEMPERATURAS MÁXIMAS E MÍNIMAS}

As Figuras 05 e 06, 07 e 08 mostram as médias diárias das temperaturas máximas e temperaturas mínimas para os períodos mais chuvosos e menos chuvosos para anos de ocorrência de El Niño e La Niña em Belém do Pará, respectivamente, e observa-se o mesmo comportamento em ambos os períodos mais chuvosos quanto menos chuvosos, porém, as médias de temperaturas máximas encontram-se mais elevadas no período menos chuvoso enquanto que as médias de temperaturas mínimas encontram-se muito próximas em ambos os períodos.

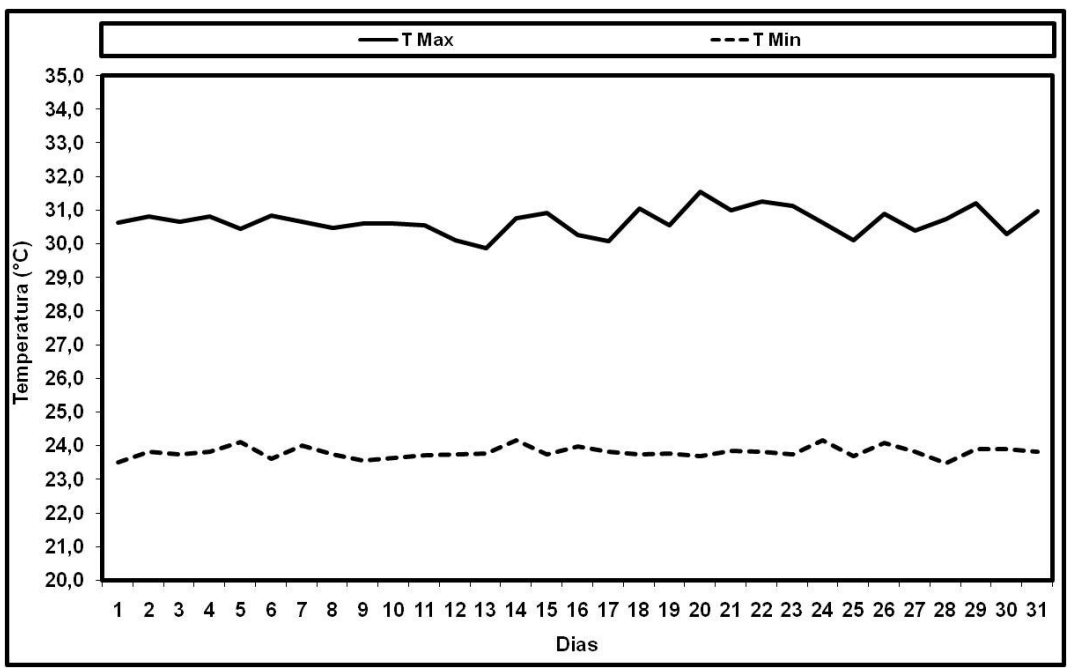

Figura 05. Temperaturas Médias Máximas e Mínimas para Período mais Chuvoso (FEV, MAR, ABR) em Anos de El Niño.

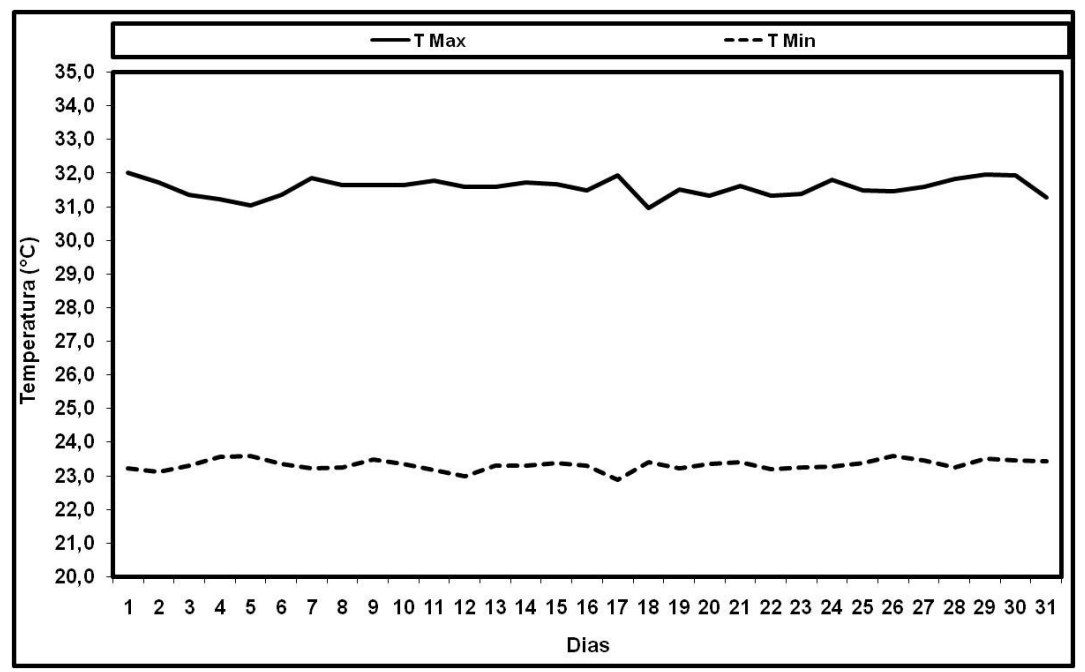

Figura 06. Temperaturas Médias Máximas e Mínimas para Período menos Chuvoso (SET, OUT, NOV) em Anos de El Niño. 


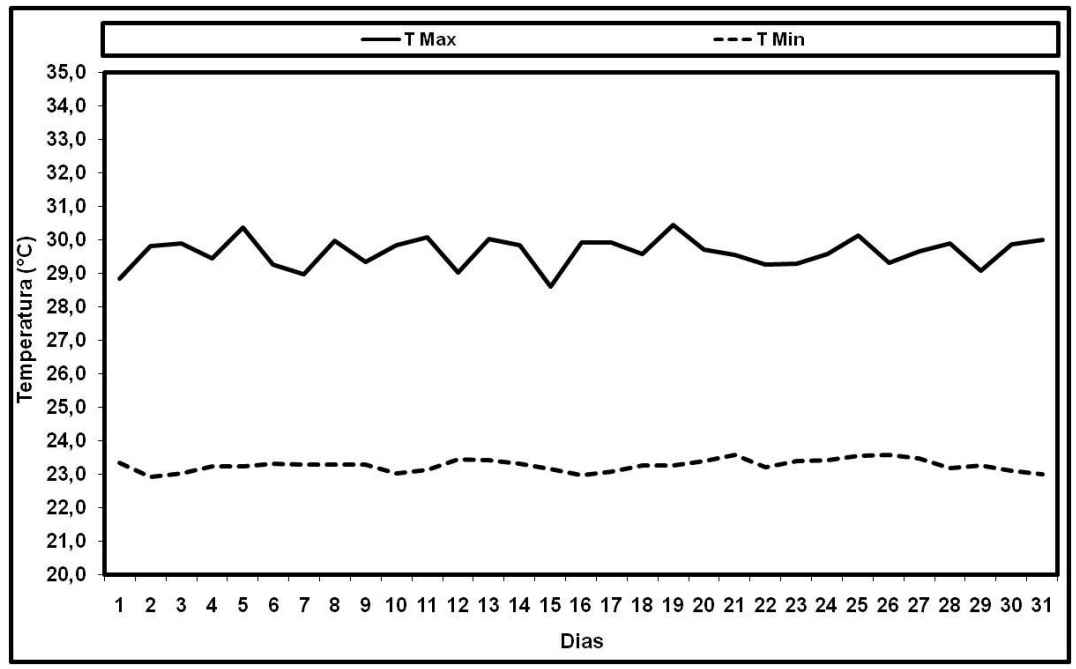

Figura 07. Temperaturas Médias Máximas e Mínimas para Período mais Chuvoso (FEV, MAR, ABR) em Anos de La Niña.

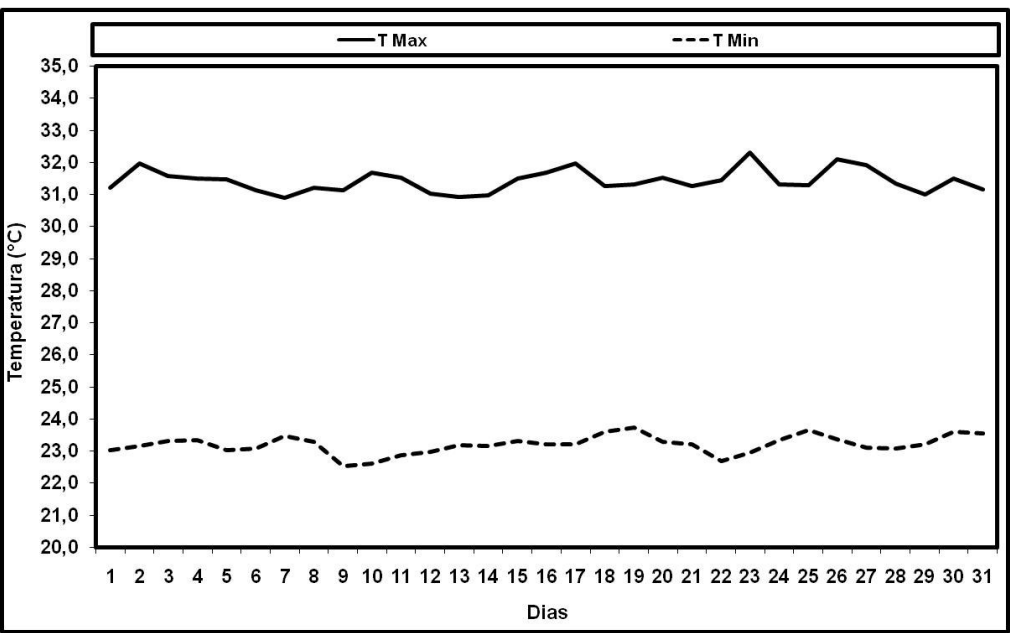

Figura 08. Temperaturas Médias Máximas e Mínimas para Período menos Chuvoso (SET, OUT, NOV) em Anos de La Niña.

Também é possível observar que em anos do fenômeno El Niño as médias de temperatura máxima são mais elevadas do que no ano da ocorrência de La Niña em função da intensificação da precipitação, pois a atmosfera encontra-se mais fria, justificando a diminuição do comportamento da temperatura média máxima.

As temperaturas médias mínimas não sofreram influência dos fenômenos EL Niño e La Niña em ambos os períodos, mais chuvosos e menos chuvosos, respectivamente, apresentando comportamento quase que constantes.

\subsection{TEMPERATURA MÉDIA HORÁRIA (VARIAÇÃO DIURNA)}

As Figuras 09 e 10 mostram a variação diurna média horária da Temperatura do Ar em anos de EL Niño e La Niña, para os períodos mais chuvosos e menos chuvosos para Belém do Pará, respectivamente.

\section{4}


Observa-se que a média da temperatura do ar é maior no período menos chuvoso, sendo que, em ambos os fenômenos, El Niño e La Niña, apresentou comportamento semelhantes. Nota-se que no ciclo diário o valor mínimo ocorre pouco antes do nascer do sol, aproximadamente as 06:00 Horas e o valor máximo uma hora depois da culminação do Sol, aproximadamente as 13:00 horas.

Em anos de El Niño e La Niña, período mais chuvoso as médias as 06:00 horas foram de $24,0^{\circ} \mathrm{C}$ e $23.4^{\circ} \mathrm{C}$, enquanto que as máximas que ocorreram as 13:00 horas foram de $29,7^{\circ} \mathrm{C}$ e $28,5^{\circ} \mathrm{C}$ no período menos chuvoso. No período menos chuvoso em anos e El Niño e La Niña as mínimas foram de $23,4^{\circ} \mathrm{C}$ e $23,3^{\circ} \mathrm{C}$ e as máximas foram de $31,1^{\circ} \mathrm{C}$ e $30,9^{\circ} \mathrm{C}$, respectivamente.

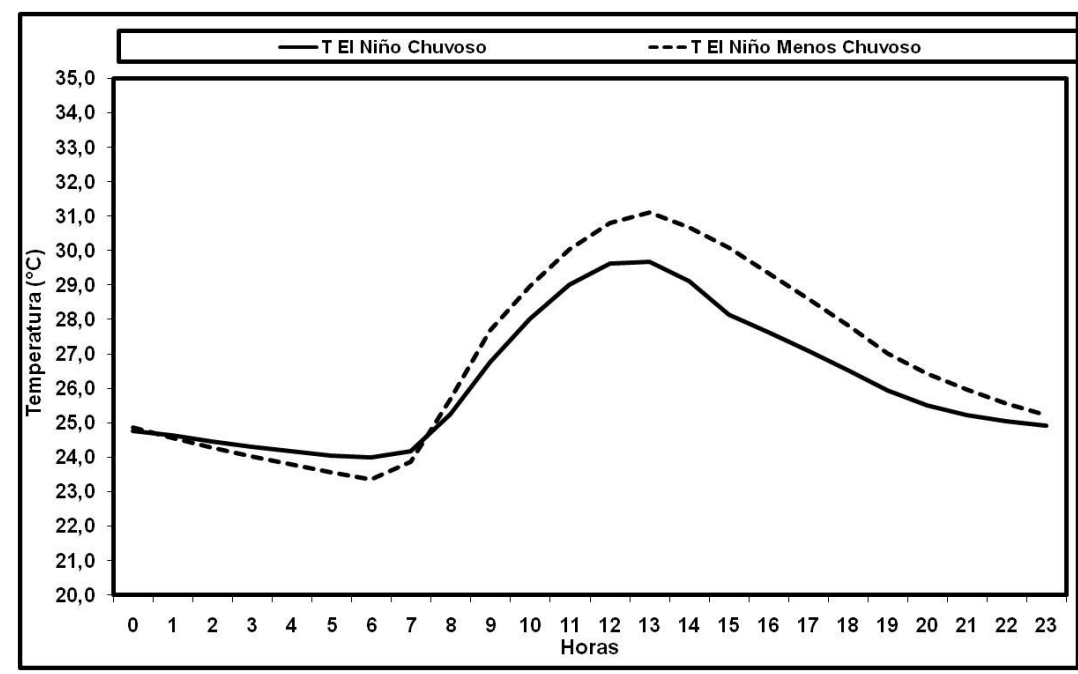

Figura 09. Variação Diurna da Temperatura do Ar em Ano de El Niño para o período mais chuvoso (FEV, MAR, ABR) e menos chuvoso (SET, OUT, NOV).

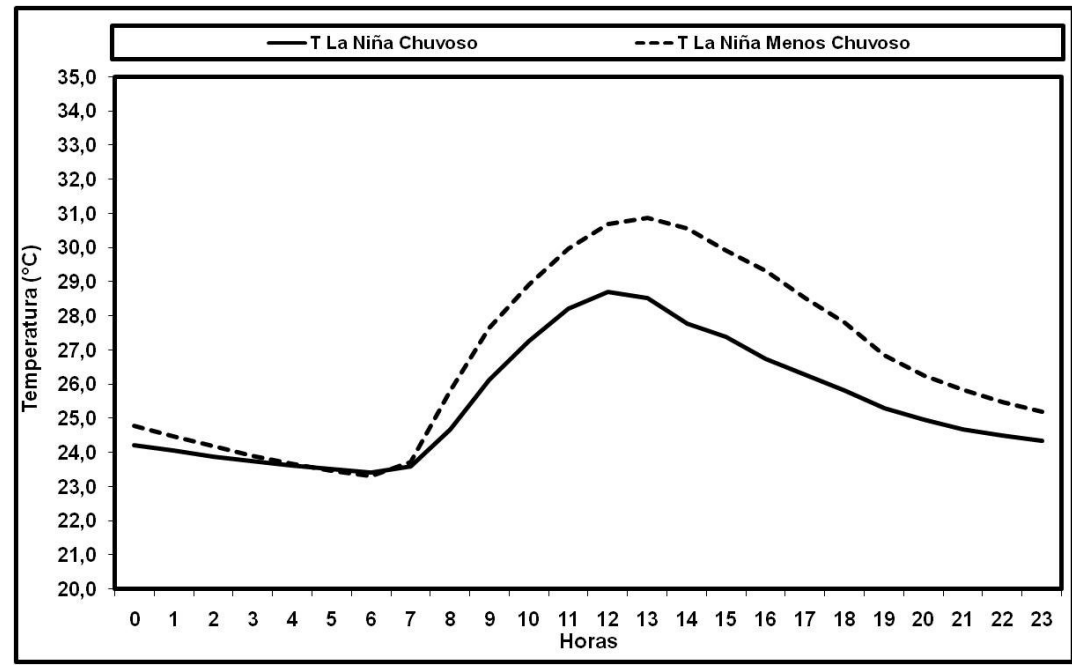

Figura 10. Variação Diurna da Temperatura do Ar em Ano de La Niña para o período mais chuvoso (FEV, MAR, ABR) e menos chuvoso (SET, OUT, NOV). 
A comparação da variação diária da temperatura do ar revela que, nas regiões tropicais a amplitude térmica diária são, em geral, muito mais elevadas revelando a acentuada correlação com a energia recebida do Sol.

A presença de fenômenos capazes de perturbar o estado prevalecente da atmosfera, podendo alterar a expectativa quanto aos horários prováveis de ocorrência de temperaturas extremas e suas amplitudes térmicas, como foi comprovado na analise desses resultados, pois a amplitude térmica em anos de La Niña apresentou-se mais acentuada quando comparada aos anos de El Niño.

Nas Figuras 11 e 12 observa-se pequena elevação da Temperatura média horária do Ar em anos de El Niño quando comparado com os anos de La Niña durante o período mais chuvoso e comportamento idêntico durante o período menos chuvoso, mostrando que a presença de fenômenos não foram capazes de perturbar o estado prevalecente da atmosfera.

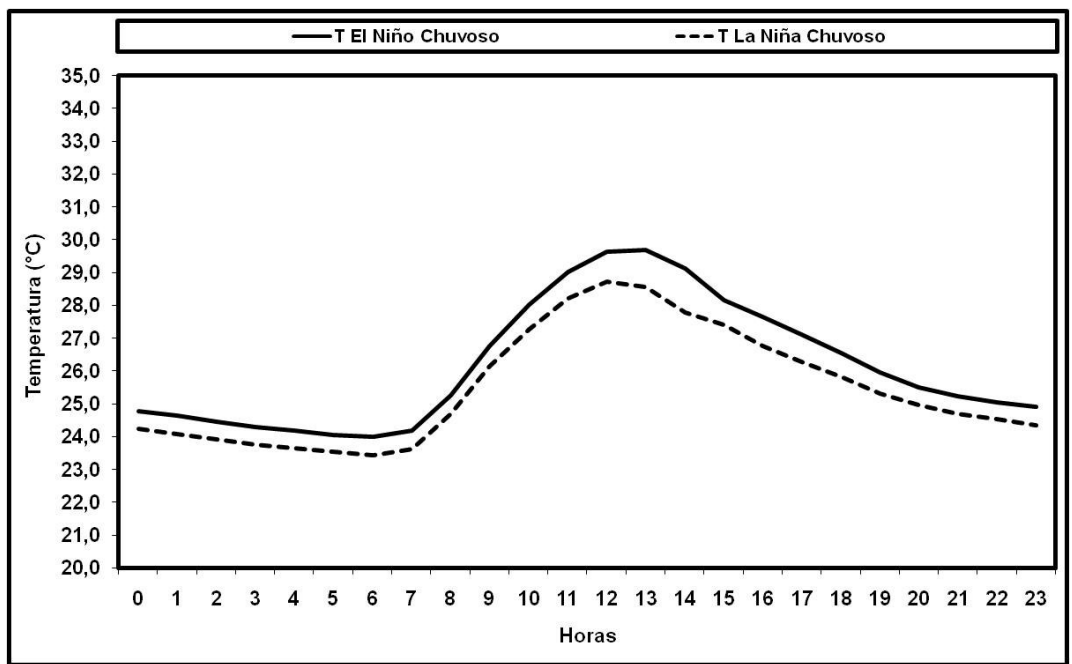

Figura 11. Variação Diurna da Temperatura do Ar em Anos de El Niño e de La Niña para o período mais chuvoso (FEV, MAR, ABR).

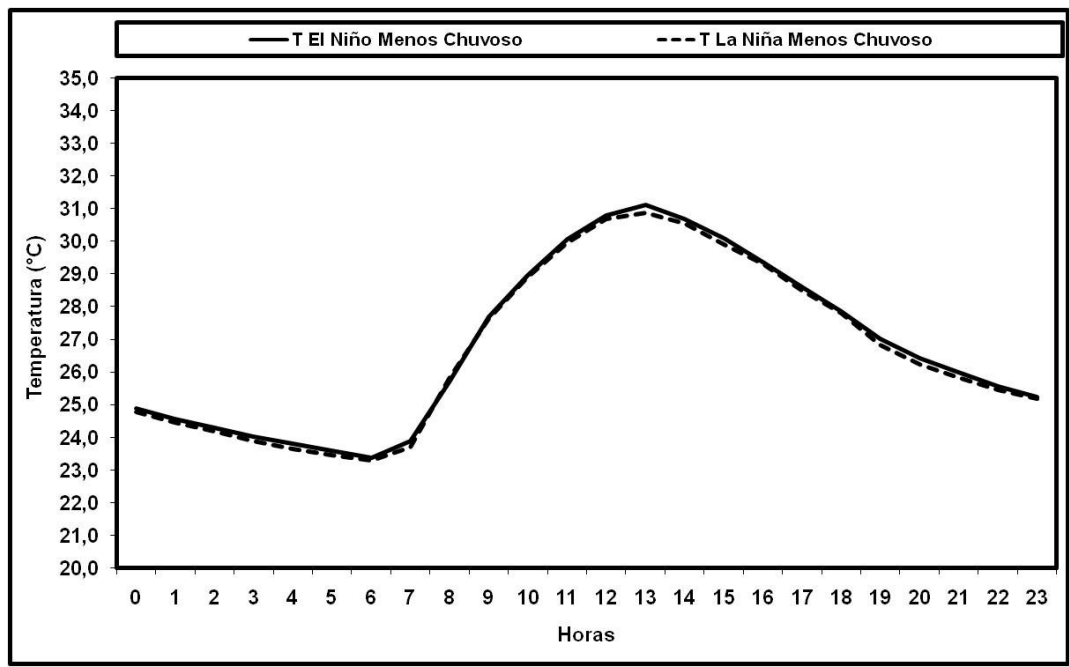

Figura 12. Variação Diurna da Temperatura do Ar em Anos de El Niño (1982, 1983, 1990, 1993) e de La Niña (1976 e 1989) para o período menos chuvoso (SET, OUT, NOV). 


\subsection{TEMPERATURAS MÉDIAS MENSAIS}

A Figura 13 mostra as médias mensais de temperatura do ar em anos de El Niño e La Niña com a Normal Climatológica de 1961 a 1990 e observa-se que a Normal apresenta média anual de $25,9^{\circ} \mathrm{C}$, enquanto que em anos de El Niño a média anual foi de $26,6^{\circ} \mathrm{C}$ e em anos de La Niña foi de $26,1^{\circ} \mathrm{C}$, mostrando que em anos de El Niño ocorre uma elevação das médias mensais e em anos de La Niña as temperaturas apresentaram valores próximos de Janeiro à Maio e no restante do ano, ou seja, de Junho a Dezembro, apresentaram valores mais elevados que a Normal, ficando muito próximas das temperaturas médias dos anos de ocorrência do El Niño, justificando que os fenômenos não influenciaram na temperatura do ar no período estudado.

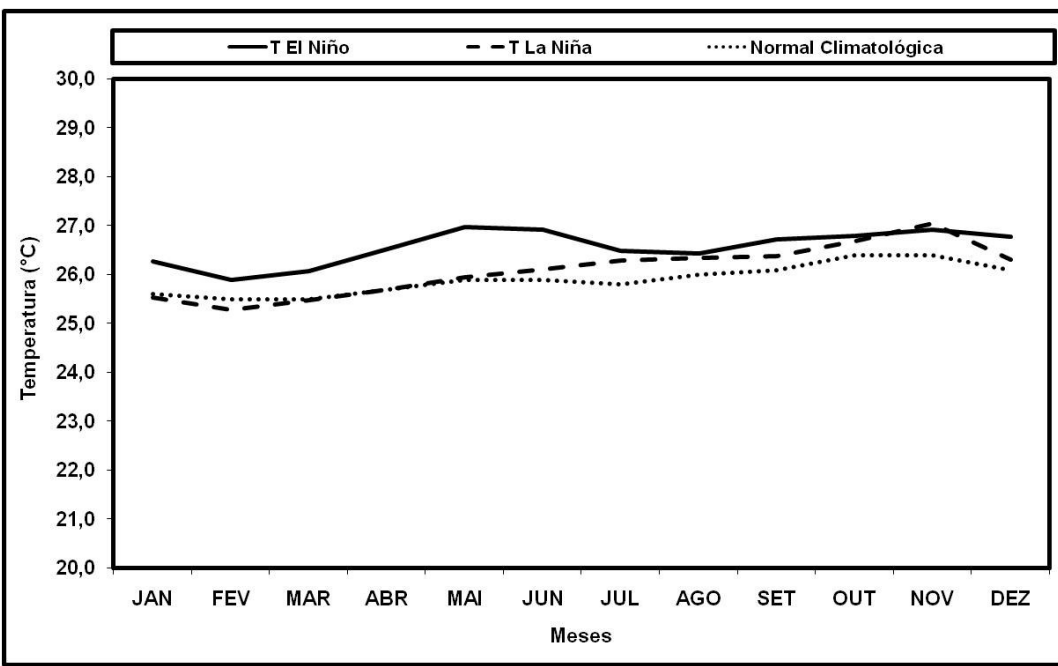

Figura 13. Temperatura Média Mensal em Anos de El Niño e La Niña comparados com a Normal Climatológica.

\subsection{DESVIO PADRÃO (DP) DA MÉDIA DAS TEMPERATURAS DO AR}

Analisando os Desvios Padrões (DP) das médias das temperaturas do ar para os períodos mais chuvosos e menos chuvosos em anos de El Niño e La Niña, observamos que as Temperaturas médias aritméticas e compensadas apresentam desvios padrões iguais, de $0,2^{\circ} \mathrm{C}$, para ambos os fenômenos e para ambos os períodos.

A temperatura média das 09:00 horas apresentou Desvio de $0,4^{\circ} \mathrm{C}$ para o período mais chuvoso e $0,2^{\circ} \mathrm{C}$ para o período menos chuvoso respectivamente. A temperatura média das 21:00 horas apresentou Desvio Padrão de $0,3^{\circ} \mathrm{C}$ e $0,4^{\circ} \mathrm{C}$ para o período mais chuvoso e menos chuvoso.

A temperatura média máxima apresentou $0,4^{\circ} \mathrm{C}$ e $0,3^{\circ} \mathrm{C}$ para o trimestre mais chuvoso e menos chuvoso, respectivamente, e a temperatura média mínima apresentou Desvio de $0,3^{\circ} \mathrm{C}$ para ambos os períodos.

Esses resultados mostram que esses valores de Desvios Padrões muito pequenos são em função do grande detalhamento de dados deste trabalho, devido ao uso das 24 observações diárias para os 06 anos estudados, validando os resultados obtidos. 


\subsection{PRECIPITAÇÃO PLUVIOMÉTRICA(PRP)}

As Figuras 14 e 15 mostram a Precipitação Média Mensal Total (PRP) para Anos de El Niño e La Niña, respectivamente, comparados à Normal Climatológica de 1961 a 1990, para Belém do Pará. Observam-se duas estações bem definidas, a estação mais chuvosa que vai de Dezembro a Maio, período esse em que a região é influenciada pela Zona de Convergência Intertropical, regionalmente chamada de inverno, e a estação menos chuvosa que vai de Junho a Novembro, regionalmente chamada de verão.

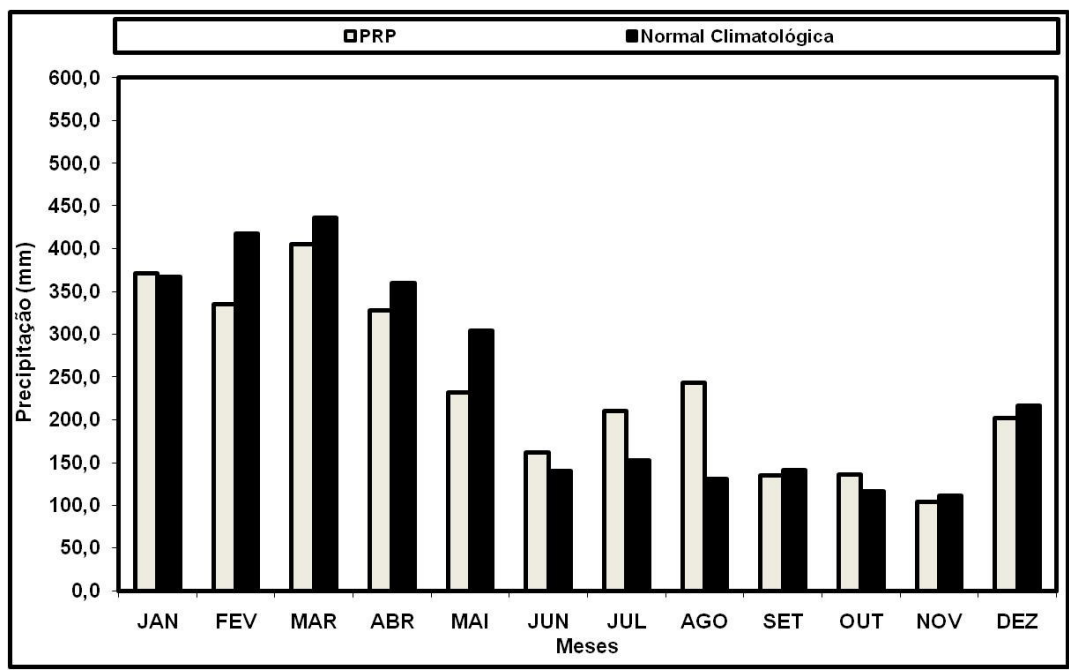

Figura 14. Precipitação Total Média em Anos de El Niño Comparada à Normal Climatológica.

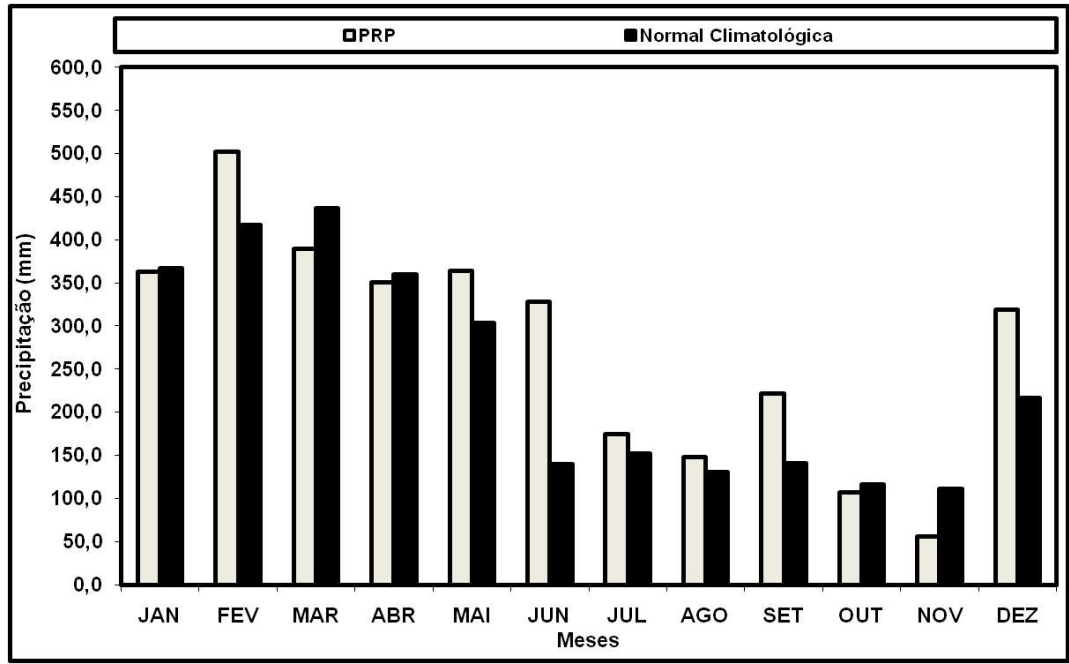

Figura 15. Precipitação Total Média em Anos de La Niña Comparada à Normal Climatológica.

Nota-se também que a Normal Climatológica apresenta Total Anual de $2.893 \mathrm{~mm}$ enquanto que em anos de El Niño a Média Total foi de $2.866 \mathrm{~mm}$ e em anos de La Niña a Média Total foi de $3.323 \mathrm{~mm}$, mostrando que em anos de 
El Niño ocorre uma redução nos totais anuais e em anos de La Niña ocorre um aumento da Precipitação.

Em anos de El Niño devido à combinação entre aquecimento anormal do Oceano Pacífico conjugado com o enfraquecimento dos ventos Alísios na região equatorial provocando mudanças nos padrões de transporte de umidade e, portanto, variações na distribuição de chuvas em regiões tropicais, provocando secas moderadas e intensas no norte e nordeste da Amazônia, enquanto que a ocorrência de Fenômeno La Niña apresenta configuração inversa, com intensificação do regime de Precipitação. Como pode ser observado com os resultados obtidos, embora tenham sido estudados somente dois anos de forte ocorrência de La Niña, alguns meses apresentaram valores acima da normal e outros meses abaixo da normal o mesmo ocorrendo em anos de El Niño.

\section{CONCLUSÕES}

Analisando os resultados obtidos no estudo das médias da temperatura média horária (24 horas), temperatura média compensada, temperatura média das 09:00 horas, temperatura média das 21:00 horas, temperaturas médias diárias máximas e mínimas e média da precipitação pluviométrica total para os anos de ocorrência dos fenômenos El Niño e La Niña e para os períodos mais chuvosos e menos chuvosos para Belém do Pará, conclui-se que:

Os Valores médios da temperatura média horária (24 horas) e média compensada estão muito próximos, enquanto que as médias das temperaturas das 09:00 horas são mais elevadas e as médias das temperaturas das 21:00 horas são menos elevadas, se distanciando das duas temperaturas, média de 24 horas e médias compensadas.

Os valores médios das temperaturas estudadas apresentaram comportamentos semelhante em anos de ocorrência dos fenômenos El Niño e La Niña e períodos mais chuvosos e menos chuvosos, porém, com a elevação/diminuição nos valores de temperatura do ar, mostrando a influência dos fenômenos na região.

Nos valores médios da variação diurna, ou temperatura média horária, observou-se que no ciclo diário o valor mínimo ocorre em torno do nascer do Sol, aproximadamente as 06:00 horas e o valor máximo uma horas depois da culminação do sol, aproximadamente às 13:00 horas, mostrando também que, em Belém as amplitudes térmicas são, em geral, mais elevadas, estando relacionadas com a maior energia recebida do Sol.

As médias da temperatura média mensal nos Anos de El Niño e de La Niña comparados com a Normal Climatológica apresentaram comportamentos próximos, porém, no período mais chuvoso os valores foram menores e na época menos chuvosa foram mais elevadas.

Os valores médios dos Desvios Padrões das temperaturas do ar foram muito pequenos, quase desprezíveis, devido ao grande número de dados utilizados nesse trabalho, variando de $0,2^{\circ} \mathrm{C}$ a $0,4^{\circ} \mathrm{C}$ nos dois trimestres (mais chuvoso e menos chuvoso) nos anos de El Niño e de La Niña, respectivamente.

Os valores médios mensais da precipitação pluviométrica apresentaram dois períodos distintos, a estação mais chuvosa, de Dezembro a Maio, e a estação menos chuvosa, de Junho a Novembro, e que na época de ocorrência dos fenômenos El Niño e La Niña alguns meses apresentaram valores acima da Normal e outro meses abaixo da Normal. 
$\mathrm{E}$, finalmente, as médias de temperaturas do ar, média horária e média diária, apresentaram significativas variações entre as diversas maneiras de cálculos das médias de temperatura e esses resultados poderão ser usados para correções e estudos gerais de climatologia e sugerir que, conforme recomendação pela OMM, que a média da Temperatura do Ar considerada como padrão, seja calculada com as 24 observações horárias das temperaturas.

\section{REFERÊNCIAS}

ARYA, S.P. Introduction to micrometeorology. London: Academic Press. Inc., 1988. 305p.

ASSIS, F.N. Anomalias pluviométricas associadas à ocorrência de El Niño e La Niña no Rio Grande do Sul, In: CONGRESSO BRASILEIRO DE AGROMETEOROLOGIA, 10., 1997, Piracicaba, SP, Anais..., Piracicaba, SP: SBAGROMET. 1 CD-ROM.

AYOADE, J.O. Introdução à climatologia para os trópicos. 4. ed., Rio de Janeiro: Editora Bertrande Brasil. S.A., 1996. 329p.

CAVALCANTI, I.F.A. Episódios El Niño/Oscilação Sul durante a década de 1986 a 1996 e sua influência sobre o Brasil. Climanálise Especial Comemorativa de 10 Anos, Outubro 1996, MCT/INPE/CPTEC, Cachoeira Paulista, SP, 52-64.

ENFIELD, D.B. El Niño past and present, Reviews of Geophysics, 1989. 27p.

GALVANI, E.; PEREIRA, A.R. Episódios El Niño/Oscilação Sul (ENOS), quantificação e classificação da intensidade do fenômeno, In: CONGRESSO BRASILEIRO DE AGROMETEOROLOGIA, 10., 1997, Piracicaba, SP, Anais..., Piracicaba, SP: SBAGROMET. 1 CD-ROM.

INSTITUTO NACIONAL DE METEOROLOGIA (INMET). Normais climatológicas (1961-1990). Brasília, DF: INMET, 1992.

KAUSKY, V.E.; CAVALCANTI, I.F.A. Eventos Oscilação Sul/EI Niño, características, evolução e anomalias de precipitação. São Paulo: INPE/CNPq, 1984. 44p.

NECHET, D.; ANDRADE, V.M.S. Variação diária da pressão atmosférica em Belém, em um ano de El Niño (1997). In: CONGRESSO BRASILEIRO DE METEOROLOGIA, 10., 1998, Brasília, DF, Anais..., Brasília, DF: SBMET. 1 CDROM.

NECHET, D.; PRESTE, A. C. A.; SIMÕES NETO, B. Comparação de médias diárias e mensais de temperatura do ar obtidas por vários métodos. In: CONGRESSO BRASILEIRO DE METEOROLOGIA, 10., 1998, Brasília DF, Anais..., Brasília DF: SBMET. 1 CD-ROM. 
OLIVEIRA, M.C.F. Variabilidade interanual da precipitação associada ao fenômeno El Niño em Belém-Pará, In: CONGRESSO BRASILEIRO DE METEOROLOGIA, 8., 1994, Belo Horizonte, MG, Anais..., Belo Horizonte, MG: SBMET. 1 CD-ROM.

SILVA; J. F.; El Nino - O Fenômeno climático do século. Brasília: Editora Thesaurus, 2000, 132p.

VAREJÃO-SILVA, M.A.; Meteorologia e climatologia. Brasília: INMET. Stylus Gráfica, 2001, 532p. 